Relations industrielles

Industrial Relations

\title{
Regulating Union Government, Marten S. Estey, Philip Taft, Martin Wagner, Editors, Harper \& Row Publishers, New York, Evanston and London, 1964, 230 pages.
}

\section{Marc Poulin}

Volume 20, numéro 3, 1965

URI : https://id.erudit.org/iderudit/027593ar

DOI : https://doi.org/10.7202/027593ar

Aller au sommaire du numéro

Éditeur(s)

Département des relations industrielles de l'Université Laval

ISSN

0034-379X (imprimé)

1703-8138 (numérique)

Découvrir la revue

Citer ce compte rendu

Poulin, M. (1965). Compte rendu de [Regulating Union Government, Marten S. Estey, Philip Taft, Martin Wagner, Editors, Harper \& Row Publishers, New York, Evanston and London, 1964, 230 pages.] Relations industrielles / Industrial Relations, 20(3), 575-575. https://doi.org/10.7202/027593ar

Tous droits réservés @ C Département des relations industrielles de l'Université Laval, 1965
Ce document est protégé par la loi sur le droit d'auteur. L'utilisation des services d'Érudit (y compris la reproduction) est assujettie à sa politique d'utilisation que vous pouvez consulter en ligne.

https://apropos.erudit.org/fr/usagers/politique-dutilisation/ 


\section{RECENSIONS BOOKS REVIEW}

Manogement: Challenge and Response, par Mortin B. Corter et ol. (Eds), Holt, Rinehart and Winston, Inc., Toronto, 1965, 274 poges.

Depuis un bon nombre d'années la revue Fortune publie une brève histoire des grandes entreprises privées américaines, ainsi qu'un profil des chefs qui en ont ossuré la survie ou milieu des épreuves et des crises qu'elles ont offrontées.

Dans ce volume, les éditeurs ont rassemblé probablement les meilleurs articles de la série, afin de permettre ò l'étudiant en administration des entreprises d'établir un pont entre la théorie et la pratique. De fait, une étude personnelle des cas permet de mieux saisir comment des odministrateurs chevronnés ont dirigé et dirigent encore les activités différenciées qui se déploient ou sein de la grande organisation. Une analyse intensive et comparative de chaque cas permet aussi de saisir la façon dont les décisions sont prises à un moment critique et la personnalité de ceux qui les prennent.

\section{Laurent Bélanger}

Regulating Union Government, Marten S. Estey, Philip Taft, Martin Wagner, Editors, Harper \& Row Publishers, New York, Evanston and London, 1964, 230 pages.

Ce volume est le fruit de la collaboration de Joel Seidman, Sar A. Leviton, J. Joseph Loewenberg, Benson Soffer, Emanuel Stein, Howard Jenkins, Jr. and D. Stewart. Chacun de ces auteurs a écrit un chapitre oyant trait de foçon directe ou indirecte au - Labor-Management Reporting and Disclosure Act de 1959, mieux connu sous le nom de Loi Landrum-Griffin. Les éditeurs ont tenté de grouper une série de chapitre pour foire ressortir l'arrière-plan de cette loi, la façon dont elle est administrée, ce qu'elle a permis d'apprendre sur la conduite et l'administration des syndicats, et ses conséquences sur lo convention collective.

Dans un premier chapitre, Seidman étudie les critiques croissantes qui 's'élevaient contre la corruption syndicale ovant l'adoption du LMRDA. De leur côté, Leviton et Loewen- berg donnent une description des enquêtes sénatoriales et des problèmes juridiques qui ont précédé la loi. Dans un troisième chapitre, Stewart donne une description et une appréciation de l'organisation, des fonctions et des activités du « Bureau of Labor-Manogement Reports . Soffer, lui, conclut que la loi n'a eu que des effets négligeables sur la convention collective et il prévoit qu'il en sera de même dans les années ò venir. Les implications du LMRDA sur les finances des syndicats sont étudiées par Stein. Dans le chapitre suivant, Jenkins démontre que la loi n'est encore qu'une tentative de démocratisation $\triangleright$, en ce qui concerne les élections dans les unions de métier. En dernier lieu, Marten S. Estey commente les recherches et les stotistiques du BLMR durant les quatre premières années de son entrée en vigueur.

D'une lecture facile à couse de son style bien approprié, cet ourrage constitue une excellente critique des évènements syndicaux et juridiques qui ont conduit à l'adoption de la loi Landrum-Griffin en 1959, des répercussions et de l'efficacité de cette loi sur diverses activités syndicoles, en particulier les finances, les élections et la convention collective.

Cependant, les outeurs le reconnaissent aussi, il est trop tôt pour déterminer les effets précis de la loi sur la conduite des syndicats. Mais les recherches de ces auteurs permettent déjà de déceler les faiblesses et l'efficacité de la loi, ainsi que de vérifier si les accusations portées contre les syndicats ovant 1959 étaient fondées ou non. Malheureusement, il semble que le BLMR ne fournit pas beaucoup de données sur les structures syndicales et les effectifs oux différents niveaux de ces structures.

\section{Marc Poulin}

Gestion de I'entreprise, por Jane AubertKrier, Presses universitaires de France, Paris, 1962, 615 poges.

L'auteur affirme dans son introduction que celui qui l'aborde (l'enseignement de l'administration) doit éviter trois écueils: tout traiter mais de foçon trop sommaire, aborder les difficultés mais de façon telle- 